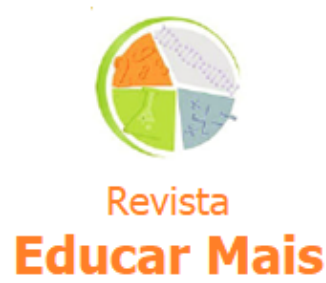

\title{
Contributos da componente curricular História da Matemática na formação inicial do professor de matemática
}

\author{
Contributions of the curricular component History of Mathematics \\ in the initial formation of the mathematics teacher
}

Andressa Abreu da Silva1; Kátia Arcaro²; Rodrigo Sychocki da Silva³

\begin{abstract}
RESUMO
O presente texto organiza-se a partir de uma pesquisa realizada com professores de matemática que cursaram durante a formação inicial a componente curricular História da Matemática. A pesquisa teve por objetivos investigar se os participantes que já atuam como docentes fazem uso da História da Matemática em suas aulas e como estes entendem o processo de construção do conhecimento. Para tanto, foi feito e usado um desenho metodológico qualitativo, no qual foram feitas uma exploração e a análise de um questionário respondido por licenciados e licenciandos já atuantes que tiveram sua formação inicial no Instituto Federal de Educação, Ciência e Tecnologia do Rio Grande do Sul, Campus Caxias do Sul. Pode-se concluir que a componente curricular História da Matemática desempenhou um importante papel na formação inicial dos consultados, bem como contribui na sua prática docente. Como principais contribuições, os pesquisados destacam a mobilização do conhecimento e a provocação da curiosidade dos estudantes durante as aulas de matemática.
\end{abstract}

Palavras-chave: Educação Matemática; Formação de Professores; História da Matemática; Licenciatura em Matemática.

\begin{abstract}
The present text is organized from a research carried out with teachers of mathematics who studied during the initial formation the curricular component History of Mathematics. The aim of the research was to investigate whether the participants who already act as teachers make use of the History of Mathematics in their classes and how they understand the process of knowledge construction. For that, a qualitative methodological design was made and used, in which an exploration and analysis of a questionnaire answered by graduates who had their initial formation in the Federal Institute of Technology of Rio Grande do Sul, Caxias do Sul campus was done and used. To conclude that the curriculum component History of Mathematics played an important role in the initial formation of those consulted, as well as contributing in their teaching practice. As main contributions, the respondents highlight the mobilization of knowledge and the provocation of students' curiosity during math classes.
\end{abstract}

Keywords: Mathematics Education; Teacher Training; History of Mathematics; Major in Mathematics.

\footnotetext{
${ }^{1}$ UCS - Universidade de Caxias do Sul, Caxias do Sul/RS - Brasil.

2 IFRS - Instituto Federal de Educação, Ciência e Tecnologia do Rio Grande do Sul, Caxias do Sul/RS - Brasil.

3 UFRGS - Universidade Federal do Rio Grande do Sul, Porto Alegre/RS - Brasil.
} 


\section{INTRODUÇÃO}

A Educação Matemática volta-se para o desenvolvimento de estratégias de articulação entre teoria e prática, bem como para o fomento do interesse dos alunos pelo aprendizado e de seus educadores pelo ensino. Toujá (2014) afirma que os alunos consideram a Matemática importante em sua formação básica e, embora mais de $90 \%$ dos alunos consultados afirmem isso, eles não sabem exatamente para que serve a Matemática e menos ainda qual sua importância no cotidiano. Isto pode ser visualizado no excerto:

Os $93 \%$ foram divididos em outras cinco categorias. A categoria dos que acham que é importante, entretanto não apresentaram qualquer justificativa para isso. Aqueles que apresentam o conhecido argumento de que a matemática tem como prerrogativa o desenvolvimento do raciocínio. Há também os que disseram que depende da profissão que se escolher. Outros dizem que é importante, mas não em tudo, sem, entretanto, dizer no que ela é importante e no que não é. (TOUJÁ, 2014, p. 17)

A pesquisa de Toujá (2014) evidenciou que os alunos questionados estudam Matemática, consideramna importante e afirmam que ela está presente no cotidiano, mas quando solicitado que discursem sobre o assunto, em geral, não têm domínio ou conhecimento suficiente para tal. Isso aponta para um problema que talvez extrapole a amostra da pesquisa de Toujá (2014): os alunos estudam conteúdos matemáticos sem atribuir significado a eles. Neste aspecto, o uso da História da Matemática como suporte educacional, pode colaborar na produção de significados aos estudos feitos em sala de aula.

Sendo assim, verifica-se que introduzir a História da Matemática nas aulas possa vir a oportunizar a construção de múltiplos significados ao aprendizado dos estudantes. Além disso, o contato com a História da Matemática é importante para que os alunos da Educação Básica percebam o conhecimento matemático como uma construção que ocorreu ao longo do tempo e que também a formalização dos conhecimentos, em geral, é fruto de um processo. Mas para que as práticas docentes sejam mobilizadas nesse sentido, a componente curricular História da Matemática deve ter uma participação significativa na formação de professores. Isso é ressaltado por Valente:

Como então, tratar da matemática escolar no curso de licenciatura em matemática sob a perspectiva de uma metodologia formativa do futuro professor? A resposta parece apontar para a criação de situações que coloquem o futuro docente na discussão histórico-epistemológica da constituição da matemática escolar. A organização dos programas, dos currículos, do significado daquilo que se ensina e a justificativa do seu ensino, em termos do que estamos considerando matemática escolar, tem uma história. Dessa maneira, o licenciando necessita apossar-se da educação matemática como ingrediente fundamental para exercício da futura profissão. (VALENTE, 2013, p. 11)

Como afirma Valente (2013), existe uma necessidade por parte do licenciando que, além de conhecer o conteúdo que trabalhará com os alunos, produza significado aos conteúdos estudados na Educação Básica. Para tal, vê-se a necessidade de que a História da Matemática seja abordada ao longo da formação inicial do professor, fazendo-se presente nas disciplinas de Estágio e também nas demais que envolvam práticas de ensino, não somente como uma disciplina isolada. Miguel e Miorim (2004) pontuam que:

[...] quando falamos, portanto, em participação da História na formação do professor de Matemática ou, mais amplamente, no processo de ensino-aprendizagem em todos os níveis, estamos concebendo essa participação de um modo tal que a linha que 
separa a Matemática da própria História da Matemática e da História da Educação Matemática se torna bastante tênue ou quase indistinta [...]. (MIGUEL; MIORIM, 2004, p. 177)

Nesse contexto, o presente estudo, recorte da pesquisa de Silva (2018), verificou de que forma a componente curricular História da Matemática é abordada e assimilada pelos professores em formação inicial no curso de Licenciatura em Matemática na instituição. Na construção do problema de pesquisa, entendeu-se que tal temática impacta implicitamente o Ensino de Matemática na Educação Básica, uma vez que, dependendo da formação inicial do docente, sua atuação profissional considerará com algum grau de complexidade possíveis abordagens de conteúdos matemáticos com aporte histórico enquanto aliado às estratégias de ensino.

Portanto, para apresentar e explanar as ideias ao longo do artigo estrutura-se o texto da seguinte maneira: a seção 2 expõe aportes teóricos que argumentam de forma favorável o uso da História da Matemática nas aulas de matemática; na seção 3 apresenta-se o caráter metodológico utilizado na pesquisa; na quarta seção são apresentados e discutidos os resultados alcançados com a pesquisa. Por fim, na seção 5 são contempladas reflexões a título de conclusão do estudo, mas que lançam luz e convidam a comunidade da Educação Matemática para uma discussão de caráter permanente e que se insere na formação inicial de professores de matemática: o quanto a componente curricular História da Matemática pode contribuir na formação inicial e qual a sua participação no planejamento e exercício docente.

\section{HISTÓRIA NA EDUCAÇÃO MATEMÁTICA E TRANSPOSIÇÃO DIDÁTICA: POTENCIALIDADES E DESAFIOS NO EXERCÍCIO DOCENTE}

O campo da História na Educação Matemática investiga aspectos relacionados às potencialidades do uso da História da Matemática em sala de aula, desde a forma com que o conteúdo é trabalhado a partir de contextualizações histórias oportunizando assim aos estudantes construir significados. Nele incluem-se estudos que têm por objeto de investigação problemas relativos às inserções da história na formação de professores de matemática ou de estudantes, em livros e em programas curriculares oficiais de ensino de Matemática (MIGUEL; MIORIM, 2004). Segundo Miguel e Miorim (2004), a questão fundamental que norteou seus trabalhos:

[...] diz respeito aos tipos de vínculo que se intenta promover entre a produção sóciohistórica do conhecimento matemático no passado e a produção e/ou apropriação pessoal desse conhecimento no presente. Em outras palavras, e mais amplamente, tal questão diz respeito a como se poderia conceber a relação entre a cultura matemática e as formas de apropriação dessa cultura no presente, sobretudo nas práticas pedagógicas escolares e nas práticas de investigação acadêmica em Educação Matemática. (MIGUEL; MIORIM, 2004, p. 10)

Embora essa relação seja relevante, a preocupação, as investigações e os estudos referentes à História da Matemática são relativamente recentes. Se considerarmos estudos internacionais, os interesses em torno das questões históricas relativas à Matemática surgiram por volta da década de 1980. No ano de 1983 ocorreu a criação do International Study Group on the Relations between the History and Pedagogy of Mathematics, em tradução livre "Grupo Internacional de Estudos das Relações entre a História e Pedagogia da Matemática", que é filiado à Comissão Internacional de Ensino de Matemática (ICMI) e criado durante a realização do workshop História na Educação Matemática que ocorreu na cidade de Toronto, Canadá (MIGUEL; MIORIM, 2004). 
No Brasil, o destaque para tal movimento em torno da História da Matemática se intensificou mais tarde, principalmente por causa da criação da Sociedade Brasileira de História da Matemática. A criação ocorreu no ano de 1999, na cidade de Vitória (ES). Pode-se afirmar, então, que a motivação e o interesse pelas questões históricas relativas à Matemática surgiram em torno da Educação Matemática (MIGUEL; MIORIM, 2004).

Para corroborar a relevância do uso da História da Matemática no ensino, há autores que fazem uso do "princípio genético". Essa expressão é utilizada para designar uma versão pedagógica da "lei biogenética" de Ernst Haeckel (1834-1919) que sugere que durante o seu desenvolvimento o embrião humano atravessaria os mais importantes estágios pelos quais teriam passado seus ancestrais adultos (RONAN apud MIGUEL; MIORIM, 2004). Enquanto isso, a versão pedagógica dessa lei "considera que todo indivíduo, em sua construção particular do conhecimento, passaria pelos mesmos estágios que a humanidade teria passado na construção desse conhecimento" (MIGUEL; MIORIM, 2004, p. 40).

O uso da História da Matemática, além de ser incentivado por estudiosos e professores de Matemática, é defendido para a formação de professores de Matemática e também para a Educação Básica, tendo então apoio nos Parâmetros Curriculares Nacionais (PCN). Os PCN (BRASIL, 1998) atribuem importância à resolução de problemas, buscando argumentos relacionados ao desenvolvimento histórico da Matemática para justificar a importância do trabalho com problemas históricos, isto é, usar História da Matemática com situações-problema em sala de aula como ponto de partida para os conteúdos, e não catalisar e concentrar-se apenas na sua definição.

A própria História da Matemática mostra que ela foi construída como resposta a perguntas provenientes de diferentes origens e contextos, motivadas por problemas de ordem prática (divisão de terras, cálculo de créditos), por problemas vinculados a outras ciências (Física, Astronomia), bem como por problemas relacionados a investigações internas à própria Matemática (BRASIL, 1998, $p$. 40).

Os PCN consideram que a História da Matemática possa oferecer uma importante contribuição ao processo de ensino e aprendizagem dessa área do conhecimento, estabelecendo comparações entre os conceitos e processos matemáticos do passado e do presente. Assim, permite ao professor criar condições para que o aluno desenvolva atitudes e valores mais favoráveis diante desse conhecimento (BRASIL, 1998). Também afirma que a História da Matemática possa ajudar os alunos a assimilarem e construírem conceitos:

Em muitas situações, o recurso à História da Matemática pode esclarecer ideias matemáticas que estão sendo construídas pelo aluno, especialmente para dar respostas a alguns porquês e, desse modo, contribuir para a constituição de um olhar mais crítico sobre os objetos de conhecimento. (BRASIL, 1998, p. 43)

Assim, considera-se que a própria história dos conceitos possa sugerir caminhos para a abordagem destes, colaborando na construção dos conceitos pelos estudantes e mostrando potenciais relações que a Matemática tem no cotidiano. Vale ressaltar que a História da Matemática deve ser usada como um recurso que acrescente no desenvolvimento de conceitos e não apenas reduzida a nomes, datas e fatos a serem memorizados (BRASIL, 1998).

Toujá (2014) menciona que a utilização da História da Matemática colabora a evidenciar a Matemática como construção humana e que a mesma também possa ajudar na percepção da importância e utilidade da Matemática a partir dos problemas históricos. Tal como afirmam Miguel e Miorim (2004), 
os problemas históricos devem ser utilizados como uma potencial atividade mobilizadora do conhecimento e não tornar a História um conteúdo a parte, pois desvincularia os conhecimentos e só tornaria a História da Matemática como um conteúdo a mais a ser estudado.

Assim, percebe-se que a História da Matemática possa ter um espectro mais amplo de abrangência em sala de aula do que responder simplesmente questionamentos. Os alunos constantemente questionam o professor: "Mas em que usarei isso na minha vida?". Essa pergunta não deve ser respondida da mesma forma que fez Euclides, que, ao defrontar-se com uma questão semelhante, ordenou a um escravo que desse uma moeda a seu discípulo para que pudesse ver os frutos e ter algum lucro com o que estava aprendendo (AABOE, 2013). Ao professor cabe fazer com que conteúdos mais difíceis e distantes da realidade sejam entendidos pelos alunos, processo que chamamos de Transposição Didática (LEIVAS; CURY, 2009).

A Transposição Didática tem preponderante participação na vida do professor, estando conectada à capacidade do docente de mobilizar e dissertar sobre o conhecimento para que o mesmo seja assimilado e compreendido pelo estudante. Além disso, é de suma importância que o professor saiba fazer uso da mesma para melhor desempenho em sala de aula e, que, nessa questão, a História da Matemática possa servir como recurso pedagógico para assimilação do conteúdo a ser estudado.

Quando se fala de práticas pedagógicas, incluindo seleção de conteúdos, adequação de linguagem e até mesmo de estratégias pedagógicas, é importante ressaltar o conceito de Transposição Didática. Pais (2011) afirma que a Transposição Didática pode ser entendida como um processo de sucessivas transformações, que ocorre ao longo da evolução das ideias. A definição de Transposição Didática por Chevallard (1991 apud PAIS, 2011, p. 19),

Um conteúdo do conhecimento, tendo sido designado como saber a ensinar, sofre desde então um conjunto de transformações adaptativas que vão torná-lo apto a tomar o seu lugar entre os objetos de ensino. $O$ 'trabalho' que, de um objeto de saber a ensinar faz um objeto de ensino, é chamado transposição didática.

Transposição Didática é a partir do ponto de vista teórico estudado para o presente texto e da colocação do próprio autor, o trabalho de adaptar um conteúdo para que ele possa ser atingível pelos alunos, isto é, para que os alunos consigam entendê-lo. Trata-se de tornar o conhecimento mais próximo da realidade do aluno. Segundo Nardin (2012), isso não ocorre porque o objeto de estudo é simplificado, mas sim, pois o assunto é transformado por meio de procedimentos didáticos, contextualização e adequação da linguagem. No tocante ao ensino da matemática um dos problemas que ainda persiste nos dias de hoje refere-se ao distanciamento dos conteúdos trabalhados com a realidade do estudante. Isso ocorre porque a Matemática é, ainda, considerada uma disciplina "rígida", fazendo com que os professores tenham receio de criar métodos alternativos, atendo-se unicamente aos métodos unidirecionais de ensino. A apresentação axiomática transmite a ideia do ensino matemático subsidiado na apresentação do conteúdo por meio de uma sequência rígida, na qual os conteúdos sucessores estão em dependência com os anteriores, seja por meio das definições ou demonstrações.

O método axiomático passa a impressão que seja o mais fácil de ser aplicado, pois não mostra a construção de determinado conhecimento. Embora pareça que o professor cumpriu seu papel, ele não percebe que não transformou o conhecimento em um saber a ensinar, mas apenas o apresentou em sua forma original ao aluno. A apresentação axiomática tende a esconder a história e a sucessão 
de questionamentos e formação de conceitos que são importantes. Tal método é responsável (no ensino matemático) pelo distanciamento entre o conteúdo e o aluno, pois deixa o conteúdo ser unicamente teórico, com linguagem por vezes não tão acessível (LEIVAS; CURY, 2009). Por isso, destaca-se que haja Transposição Didática, com a finalidade de que o conteúdo se torne adequado ao ser ensinado.

Sendo assim, pode-se perceber que o campo de pesquisa de História na Educação Matemática tem relação com as ideias da Transposição Didática, e que ambas têm autores com argumentos convergentes para o seu uso durante o exercício docente. Para finalizar a seção menciona-se que as ideias aqui apresentadas incitam que o uso da História da Matemática no ensino seja uma estratégia desafiadora a ser usada pelo professor em sala de aula, e que a mesma possa oportunizar a construção do conhecimento por parte do estudante.

\title{
3. APORTE METODOLÓGICO: MATERIAIS E MÉTODOS
}

O trabalho de pesquisa seguiu uma perspectiva de abordagem qualitativa. Caracterizou-se como pesquisa qualitativa, pois apresenta as respostas de um questionário aplicado a 11 licenciandos e 5 licenciados atuantes na docência por meio de percepções e análises de dados não quantitativos.

Flick (2009) afirma que a pesquisa qualitativa é a pesquisa não quantitativa ou não padronizada e dispõe de várias características próprias, usando textos como material empírico (em vez de números), partindo da noção da construção social das realidades em estudo e está interessada nas perspectivas dos participantes, em suas práticas do dia a dia e em seu conhecimento cotidiano relativo à questão em estudo.

\begin{abstract}
A pesquisa qualitativa é uma atividade situada que posiciona o observador no mundo. Ela consiste em um conjunto de práticas interpretativas e materiais que tornam o mundo visível. Essas práticas transformam o mundo, fazendo dele uma série de representações, incluindo notas de campo, entrevistas, conversas, fotografias, gravações e anotações pessoais. Nesse nível, a pesquisa qualitativa envolve uma postura interpretativa e naturalística diante do mundo. Isso significa que os pesquisadores desse campo estudam as coisas em seus contextos naturais, tentando entender ou interpretar os fenômenos em termos dos sentidos que as pessoas thes atribuem. (DENZIN; LINCOLN, 2005, p. 3)
\end{abstract}

Pode-se perceber que a pesquisa qualitativa busca compreender e analisar o objeto de pesquisa em relação ao seu meio natural, não o isolando de seus contextos e posicionando a pesquisa em relação ao meio do objeto pesquisado. Com isso em vista, para coleta dos dados foi criado e usado um questionário, que segundo Gerhardt e Silveira (2009, p. 69) é:

[...] um instrumento de coleta de dados constituído por uma série ordenada de perguntas que devem ser respondidas por escrito pelo informante, sem a presença do pesquisador. Objetiva levantar opiniões, crenças, sentimentos, interesses, expectativas, situações vivenciadas. A linguagem utilizada no questionário deve ser simples e direta, para que quem vá responder compreenda com clareza o que está sendo perguntado.

As perguntas do questionário podem ser consideradas perguntas abertas, pois o informante responde livremente, da forma que desejar (GERHARDT; SILVEIRA, 2009). As autoras consideram como vantagens do uso do questionário a economia de tempo e economia pessoal, obtenção de respostas mais rápidas e mais precisas, mais segurança aos entrevistados, pois as respostas não são 
identificadas, menor risco a distorções, além de proporcionar maior liberdade nas respostas por causa do anonimato. As perguntas feitas aos licenciados e licenciandos foram enviadas para o endereço de e-mail pessoal do participante, juntamente com o termo de consentimento. As respostas foram coletadas por meio de uma ferramenta de questionário online que organiza e armazena as respostas em nuvem, sendo assim dispensado o uso de papel e marcação de horário para a coleta das informações. As perguntas estão expostas na Figura 1 a seguir.

Figura 1: Questionário aplicado com os participantes.

1) Você considera que a componente curricular História da Matemática contribuiu em sua formação inicial para ser professor de Matemática? Justifique.

2) Durante as disciplinas de Práticas de Ensino e Estágio supervisionado a * componente curricular História da Matemática se fez presente de alguma forma? Justifique.

3) Além das disciplinas mencionadas em (2), há outras cursadas por você na licenciatura que faziam uso da componente curricular História da Matemática? Se sim, quais?

4) A sua formação inicial em Licenciatura em Matemática impacta na sua atuação profissional? Justifique.

5) Qual o seu posicionamento sobre a abordagem dos conceitos matemáticos em conexão com a História da Matemática no que se refere ao aprendizado da matemática? Justifique.

6) Você utiliza a História da Matemática, enquanto estratégia pedagógica, durante a abordagem de algum conceito? Você pode mencionar alguma situação específica?

7) A História da Matemática constitui um elemento que possa fazer parte da formação dos estudantes no Ensino Básico? Justifique.

8) Para finalizar. Qual seu posicionamento sobre o conhecimento matemático existente? Criação ou descoberta? Esforço ou acaso? Justifique.

9) Você já concluiu sua graduação em Licenciatura em Matemática? *

Fonte: Silva (2018, p. 50 e 51) 


\section{ACHADOS DA PESQUISA: ANÁLISES E REFLEXÕES}

A presente seção apresenta um recorte das respostas produzidas pelos participantes da pesquisa. Ao todo foram consultados 23 sujeitos, dos quais 16 retornaram a mensagem em resposta ao questionário proposto. Os questionados foram identificados como QA, QB, QC e assim sucessivamente, para que seja possível acompanhar e relacionar as respostas ao longo da pesquisa, mantendo-se assim o anonimato dos respondentes. Para efeitos da proposta do artigo, apresenta-se aqui uma análise referente às questões 1 , 5, 6 e 7. As demais perguntas e respostas podem ser consultadas no texto completo da monografia de Silva (2018).

Pergunta 1: "Você considera que a componente curricular História da Matemática contribuiu em sua formação inicial para ser professor de Matemática? Justifique". O intuito dessa pergunta era verificar se os licenciandos e/ou licenciados consideram que a História da Matemática teve uma participação importante ao longo de seus estudos na instituição. O Gráfico 1 mostra o percentual de respondentes que considera que sim e o percentual que considera que não.

Gráfico 1: Percentual de respostas para a pergunta 1

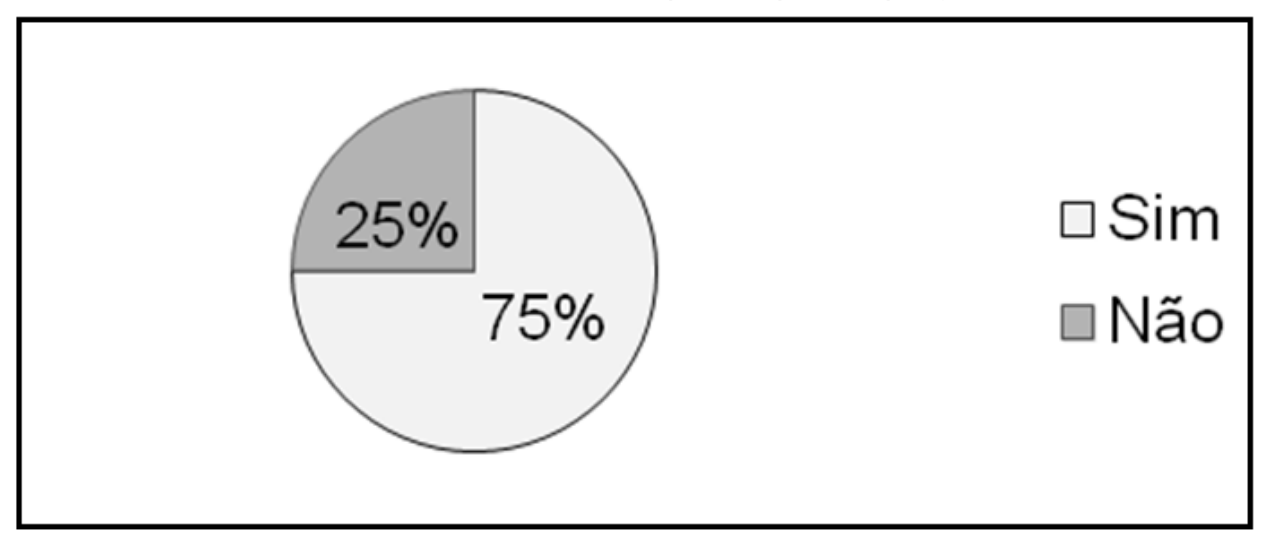

Fonte: Silva (2018, p. 24)

Nessa primeira pergunta pode-se perceber a atribuição de uma importância, por parte do questionado, que a alocação da disciplina de História da Matemática tem na sua formação inicial. Na organização curricular que os questionados cursaram, a disciplina de História da Matemática está alocada no segundo semestre. Em duas respostas constatou-se que a disciplina teria tido maior impacto na formação se estivesse mais no final do curso, conforme os Questionados G e I dizem:

QG: Não. No meu caso, a disciplina foi ofertada no início do curso, período que ainda não tínhamos conhecimento de alguns assuntos matemáticos e do que é realmente um curso de Licenciatura em Matemática, esta disciplina seria muito mais aproveitada se tivesse sido ofertada no final do curso.

QI: Não, pois tivemos esta disciplina muito no início do curso.

O Questionado K não faz alusão quanto à alocação da disciplina na organização curricular, mas avalia que foi trabalhada desvinculada das práticas de ensino, o que julga ter reduzido seu aproveitamento:

QK: Não, pois foram expostos os fatos sem link com possibilidades de inserção em práticas.

Como Miguel e Miorim (2004) afirmaram, quando tratamos do papel da História da Matemática na formação inicial do professor, a Matemática e a própria História da Matemática deveriam ser quase 
indistinguíveis, implicando que deveriam ser estudadas ao longo do curso, portanto, havendo domínio de ambas.

Essa pergunta teve três vezes mais respostas afirmativas. Dentre elas, como por exemplo, a resposta do Questionado B, que menciona entender que a História da Matemática possibilitou uma melhor compreensão dos conteúdos matemáticos, contribuindo até mesmo em sua didática em sala de aula:

QB: Sim, pois me ajudou a entender certos conceitos matemáticos, facilitando assim minha explicação para os alunos, onde fui capaz de argumentar mais sobre o assunto. Além de ser uma disciplina encantadora que me proporcionou analisar a evolução da escrita, do manuseio, das aplicações matemáticas.

Os questionados $\mathrm{D}, \mathrm{H}, \mathrm{J}$, L e M também fazem alusão ao uso da História da Matemática como apoio pedagógico:

QD: Acredito que sim, pois me proporcionou uma visão diferente de alguns tópicos da matemática, principalmente em relacionar diferentes métodos resolutivos, os quais poderiam me ajudar em abordar esses tópicos de forma diferenciada.

QH: Sim! É através da história (de onde surgiu, quem pensou, por que pensou) que é possível trazer curiosidades para nossos alunos, e além disso mostrar a eles que a matemática foi criada e pensada a fim de saciar as necessidades dos seres humanos.

QJ: Sim. Estudar história da matemática me apropriou de conhecimentos que fundamentaram e ressignificaram diversos conteúdos, especialmente do ensino fundamental, como o estudo de frações. Por exemplo, tornou-se muito mais clara pra mim a relação do sistema decimal com as frações.

QL: Sim, pois alguns conteúdos abordados na educação básica é contextualizados a partir dos que foi explorado nesta disciplina.

QM: Sim. A História da Matemática funciona como um atrativo, um motivador e como explicação parcial para alguns tópicos referentes aos conteúdos de Matemática.

Esses relatos reforçam a ideia de que a História da Matemática pode ser um recurso pedagógico a ser usado na Transposição Didática do professor. Outro elemento que surgiu nas justificativas a essa pergunta é o uso da História da Matemática como motivador para o aprendizado por meio da curiosidade. Conforme justificativa do Questionado H (acima transcrita), a História da Matemática permite aos estudantes se questionarem "de onde surgiu, quem pensou, por que pensou" em determinados conteúdos Matemáticos.

Segundo Lopes e Alves (2014, p. 1) "conhecer a origem e evolução dos assuntos dos quais se gosta é uma curiosidade natural, inerente ao ser humano." Então, o uso da História da Matemática nas aulas satisfaria a curiosidade dos estudantes que gostam da disciplina e instigaria a de outros, estimulando-os na busca pelo conhecimento.

Outro aspecto interessante é que os Questionados $\mathrm{F}$ e $\mathrm{H}$ mencionam a ideia de que a Matemática é uma área em construção e não um conhecimento pronto e acabado, tendo sido criada a partir de necessidades humanas ao longo do tempo. Nas palavras do Questionado F: 
QF: Sim, contribui. Esse componente mostra e dá uma boa ideia de que a matemática não é algo pronto e que se deu do nada e, sim, através de construções, experimentações e muitos anos de desenvolvimento.

Como o próprio PCN afirma:

A Matemática é uma ciência viva, não apenas no cotidiano dos cidadãos, mas também nas universidades e centros de pesquisas, onde se verifica, hoje, uma impressionante produção de novos conhecimentos que, a par de seu valor intrínseco, de natureza lógica, têm sido instrumentos úteis na solução de problemas científicos e tecnológicos da maior importância. (BRASIL, 1998, p. 24)

Pergunta 5: "Qual o seu posicionamento sobre a abordagem dos conceitos matemáticos em conexão com a História da Matemática no que se refere ao aprendizado da matemática? Justifique". O intuito dessa pergunta é verificar se os licenciandos/licenciados do curso entendem os conceitos matemáticos de forma que estejam interligados à História da Matemática. Além disso, tem a intenção de verificar se a História da Matemática ajuda no aprendizado dos alunos.

Essa pergunta não teve respostas negativas, no entanto, dois respondentes ( $G$ e $L$ ) consideraram somente o âmbito do Ensino Superior e não no ensino em geral, sem fazer reflexão sobre a sua prática docente. Ainda assim, seus posicionamentos acerca do uso da História da Matemática a serviço do ensino da Matemática na graduação foram considerados pertinentes:

QG: Poderia ser mais aprofundado em todas as etapas da graduação, para ter mais significado na aprendizagem para os licenciandos de matemática.

\section{QL: Acredito que poderia ser melhor explorado pelos professores da graduação.}

Essas respostas indicam que a História da Matemática poderia ter ainda maior presença na formação inicial do professor:

De fato, é importante, para a formação do professor de matemática ter conhecimento das contribuições, ao longo do tempo, de como cientistas, estudiosos e matemáticos desenvolveram e sistematizaram função como conteúdo matemático, fundamental para o professor em formação, também, é a ciência de como, a matemática que ele irá ensinar em sua profissão organizou-se/reorganizou-se levando em conta a forma escolar mutante desse conceito em diferentes épocas escolares. (VALENTE, 2013, p. 35)

Com a passagem, pode-se perceber que Valente considera que a História da Matemática pode contribuir significativamente na formação inicial do professor de Matemática, à medida em que contribui na construção do conhecimento do próprio professor " o futuro mestre irá deparar-se com a necessidade de reconstruir os conteúdos da matemática escolar presentes no ofício cotidiano de ser professor" (VALENTE, 2013, p. 34).

Destacam-se ainda outras respostas dos Questionados que consideraram importante uma abordagem da História da Matemática em sala de aula: $\mathrm{D}, \mathrm{H}$ e $\mathrm{P}$, que mencionam a construção do conhecimento a partir da história:

QD: Acredito, que alguns tópicos da matemática é importante fazer uma reconstrução histórica do conceito, para o entendimento do desenvolvimento da matemática. 
QH: Importantíssimo. É necessário trazer aos estudantes o sentido desses conceitos (por que foi pensado, por que estudá-los)

QP: Interfere em todo o sentido e compreensão do conteúdo que se está trabalhando.

Segundo os PCN, a História da Matemática pode colaborar na construção do conhecimento por parte do aluno:

Em muitas situações, o recurso à História da Matemática pode esclarecer idéias matemáticas que estão sendo construídas pelo aluno, especialmente para dar respostas a alguns porquês e, desse modo, contribuir para a constituição de um olhar mais crítico sobre os objetos de conhecimento. (BRASIL, 1998, p. 43)

A importância de fazer conexões do passado com o presente para auxiliar nos estudados realizados é evidenciado por Radford, Boero e Vasco (2000, apud MIGUEL; MIORIM, 2004, p. 131) que afirmam que "a História da Matemática é o locus mais maravilhoso no qual se pode reconstruir e interpretar o passado, a fim de abrir novas possibilidades para construir atividades para nossos estudantes".

Assim, vê-se que o recurso à História da Matemática em sala de aula ajudaria os alunos a se apropriar do conhecimento e também ter uma visão mais crítica em relação aos objetos de estudo, desenvolvendo uma importante percepção quanto às necessidades e aplicações que motivaram e motivam a propagação do conhecimento matemático. Foi mencionada pelos Questionados C, F e I a utilização da História da Matemática como mobilização do conhecimento:

QC: Acho positivo, pois auxilia na compreensão dos mesmos, incentiva, enriquece a aula, torna o aprendizado interessante.

QF: Vejo duas formas de conexão entre os conceitos matemáticos e a história da atemática; uma forma é a que apenas traz informações como datas, nomes dos matemáticos por traz do assunto, locais... já outra forma, seria fazer da história um instrumento para mobilização do conhecimento, sendo uma início para problematizações e, assim, contextualizar e tornar mais atraente os assuntos abordados.

QI: é um importante recurso no ensino aprendizagem da Matemática, ela contextualiza os conceitos podendo despertar a curiosidade do aluno. Nas escolas vimos que os conceitos matemáticos são apresentados aos alunos sem qualquer referência à sua história, dando maior ênfase aos procedimentos e técnicas.

Vê-se que os questionados mencionados consideram que a História da Matemática influencia na motivação dos alunos e que também os incentiva a estudar. Além disso, Valente (2013) considera que usar a História da Matemática é recurso comum: "a História da Matemática acaba sendo tratada como um recurso, e um dos aspectos mais comuns desse uso é o de motivar os alunos para o estudo das disciplinas matemáticas" (VALENTE, 2013, p. 33).

Essa pergunta teve uma resposta surpreendentemente positiva, pois fez com que o respondente $\mathrm{K}$ analisasse e refletisse sobre sua prática docente, percebendo que, se fizesse uso da História da Matemática poderia enriquecer suas aulas:

QK: Acredito que eu deveria me esforçar mais para aproximar dos meus planejamentos. 0 que percebo é que ao pensar na proposta da aula, busco desenvolver uma aula que faça uso de material 
concreto ou tecnologias e não me dedico em inserir a História da Matemática. Talvez eu devesse buscar exemplos de aulas com esta conexão para ter um referencial.

Assim, pode-se verificar que os Questionados consideraram que a História da Matemática deva ter significativa presença na sala de aula, para assim auxiliar na construção do conhecimento e também para motivar os estudantes. Além disso, permitiu aos próprios Questionados refletir a respeito de sua prática docente.

Pergunta 6: "Você utiliza a História da Matemática, enquanto estratégia pedagógica, durante a abordagem de algum conceito? Você pode mencionar alguma situação específica?". O intuito dessa pergunta foi verificar se os licenciandos/licenciados, enquanto docentes, faziam uso da História da Matemática em suas aulas. O Gráfico 2 mostra o percentual de respondentes.

Gráfico 2: Percentual de respostas à pergunta 6.

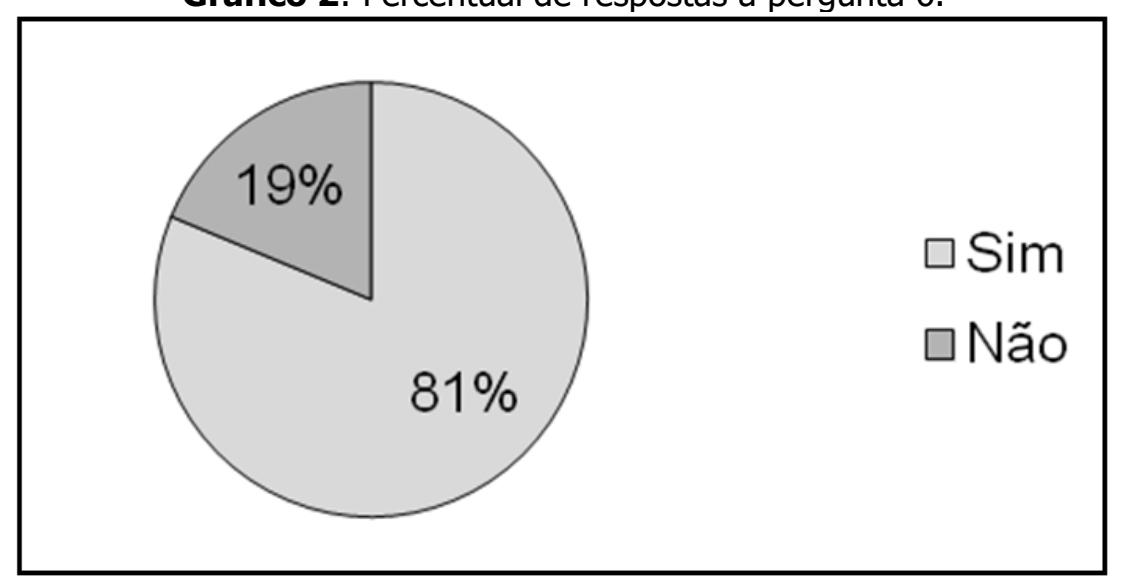

Fonte: Silva (2018, p. 36)

Essa pergunta teve somente 2 respostas negativas. Foram consideradas como respostas negativas a do respondente $K$, que não emitiu comentários, e a do respondente $C$, que menciona não ter utilizado ainda, mas ter intenção de fazê-lo:

QC: Não utilizei, pois iniciei a docência a pouco tempo, porém tenho a intenção de utilizar sim.

Embora a resposta do Questionado $C$ tenha sido considerada como negativa, essa resposta mostra que o mesmo refletiu acerca de sua prática e tem interesse em inserir a História da Matemática em suas aulas. O Questionado D menciona que a História da Matemática pode se fazer presente em sua prática docente, mas não de forma direta e em toda sua potencialidade:

QD: Ao pouco tempo que estou em atuação, acredito que ainda não utilizei como estratégia pedagógica com todas as suas ferramentas. Entretanto, ao estudar e lecionar a história da construção do sistema de numeração, e os diferentes sistemas (Alguns geométricos), talvez a história da matemática, se faz presente de forma transversal a estes tópicos, mas de forma rápida e dinâmica. Já ouvi colegas trabalharem com História da Matemática nos conteúdos de Teorema de Pitágoras e Talles.

Assim, segundo Lopes e Alves (2014) afirmam, a História da Matemática pode ser utilizada como recurso sem ser diretamente citada: "é possível também que o professor recorra a processos históricos como facilitadores ou condutores do processo de aprendizagem, sem que a História da Matemática seja explicitamente citada" (p. 2). 
Desta forma, vê-se que o Questionado D julga não explorar a História da Matemática tanto quanto poderia, embora ela se faça presente em sua prática docente. $O$ fato de considerar a possibilidade desse recurso é certamente um aspecto bastante positivo dentro do viés desta pesquisa.

Corroborando o apontamento de Lopes e Alves (2014) supracitado, destacam-se as respostas dos Questionados B e F. O primeiro afirmou que o tempo de escola é muito curto para trabalhar com a História da Matemática, mas apontou importantes situações em que o faz; e o segundo, diz que não utiliza a História da Matemática como recurso pedagógico, mas sim para instigar a curiosidade dos alunos:

QB: Às vezes, pois o tempo de escola é muito curto, mas sempre que possível eu utilizo. Já utilizei nos conteúdos sobre o surgimento dos números, áreas, trigonometria, em equações e funções com resolução de problemas históricos.

QF: Utilizo mais como uma fonte de informação e curiosidade do que como uma estratégia pedagógica.

A fala do Questionado B indica que ele desconhece ou desvalida o importante trabalho que já desenvolve, e o respondente $F$ não reconhece a mobilização do conhecimento como recurso pedagógico, ou não identifica sua prática com tal. Sendo assim, embora o Questionado F considere não utilizar a História da Matemática como um recurso pedagógico, sua resposta foi considerada como afirmativa, já que "[...] acredita-se que a presença da História da Matemática em sala de aula constitui um recurso pedagógico ao qual o professor pode recorrer para auxiliar os estudantes na construção do significado do que se está trabalhando" (LOPES; ALVES, 2014, p. 1).

Ainda dentre as respostas positivas, pode-se destacar a do Questionado J, que fala sobre os sistemas de numeração romanos e egípcios, que muitas vezes não são estudados na Educação Básica:

QJ: No sexto ano do fundamental, antes de revisar o sistema de numeração decimal, considero de suma importância estudar os sistemas de numeração anteriores através dos tempos, números romanos, egípcios e outros sistemas, contextualizando o que se sabe sobre a criação destes sistemas.

Além disso, foi mencionada a utilização da História da Matemática novamente como mobilização do conhecimento e o conteúdo de Trigonometria foi citado direta e sucintamente duas vezes, nas respostas dos questionados I e P. Algumas importantes exemplificações de contextualização histórica que os Questionados fazem seguem nas suas falas:

QA: Sim, conto a história do Papiro de Rhind, quando ensino equações no 70 ano, uso alguns problemas que foram tirados de lá para trabalhar com os alunos, uso a história do Xadrez (tenho dúvidas da veracidade, pois não é confirmada) para iniciar o conteúdo de potenciação. A história do Pi para números irracionais.

QH: Sim. Com o sexto ano, ao estudar números naturais, por exemplo. Trago a história dos números (como eram escritos, o porque foram criados, como se representava quantidade...)

QM: Sim. Por exemplo, no conteúdo de grupos em Álgebra realizei uma introdução que abordava a história de matemáticos envolvidos na criação de teorias ligadas ao tópico, como Galois e Abel. 
QN: Em alguns momentos sim, por exemplo, para começar Números Complexos apresento a história por trás da resolução de uma equação de $3^{\circ} \mathrm{grau}$, e nomes importantes Fontana - Tartaglia, Cardano, Bombelli, Euler, Gauss para situar os alunos no tempo-espaço e da necessidade de desse conjunto numérico. Também gosto de contar a história a da fórmula de Bháskara... entre outras situações.

QO: Sim. Por exemplo, para explicar o conceito de medida.

Os exemplos citados pelos Questionados M e O correspondem a conteúdos do Ensino Superior. Notase, portanto, que em todos os níveis de ensino essa importante ferramenta pode ser utilizada como recurso, desde que o professor tenha conhecimento e familiaridade para investir nela.

Pergunta 7: "A História da Matemática constitui um elemento que possa fazer parte da formação dos estudantes na Educação Básica? Justifique". Essa pergunta tinha por intuito verificar se os questionados consideram que existe a possibilidade de a História da Matemática integrar o currículo da Educação Básica, permeando os conteúdos da disciplina de Matemática. O Gráfico 3 mostra a distribuição do percentual de respondentes dessa pergunta.

Gráfico 3: Percentual de respostas afirmativas e negativas da pergunta.

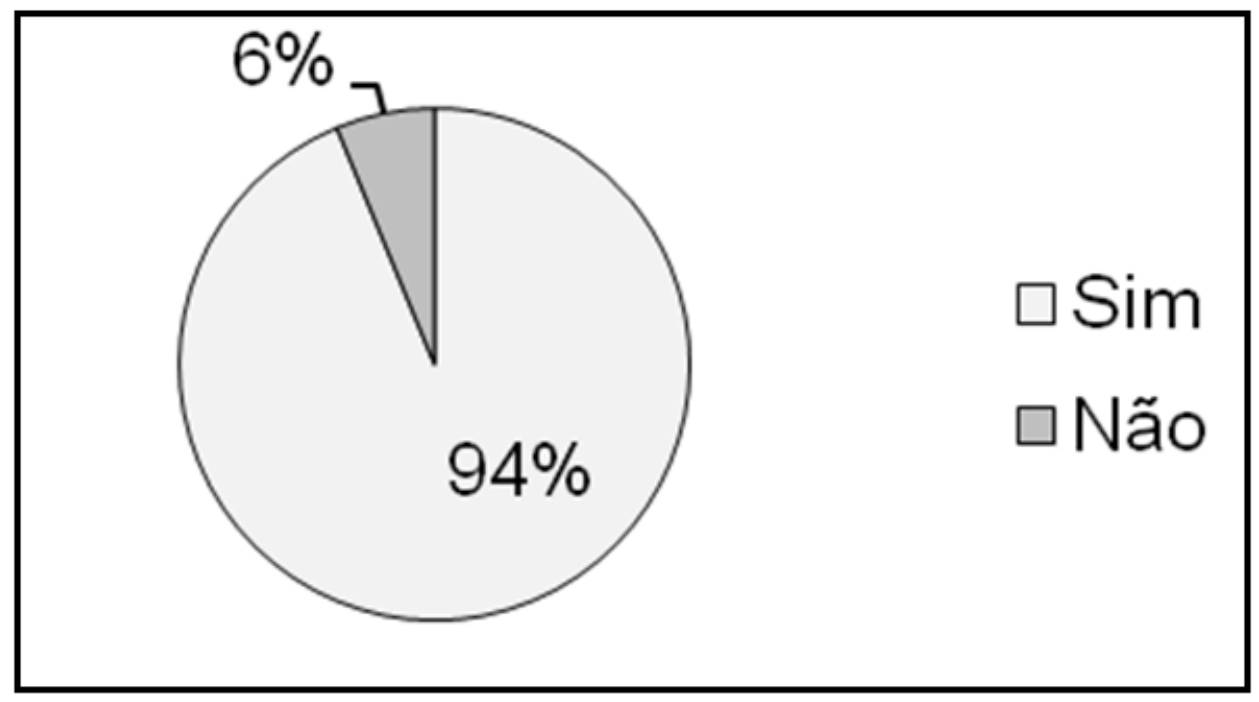

Fonte: Silva (2018, p. 39)

A única resposta negativa a essa pergunta foi a do respondente 0 , que não a respondeu do seu ponto de vista de docente, mas justificando que os alunos não gostariam de estudar a História da Matemática em sala de aula. Dentre as demais respostas obtidas, pode-se destacar que nenhum dos questionados mencionou que a História da Matemática deva ser trabalhada como uma disciplina a parte na Educação Básica (o que, de toda forma, não foi o propósito desta pergunta), no entanto, os Questionados J e M posicionam-se abertamente contrários a essa ideia:

QJ: Depende. Não deve ser estudada por si só, uma vez que o aluno não verá relação com sua vida. Deve ser estudada DURANTE o estudo dos demais conhecimentos matemáticos, de modo que cada conteúdo seja justificado por sua história, ao mesmo tempo em que justifique o estudo da mesma.

QM: Creio que ela deva fazer parte como auxílio para abordagem de conteúdos em conexões, não necessariamente como um tópico específico.

Embora o Questionado J considere que a História da Matemática não contribuiria para as relações feitas pelos alunos com o cotidiano, Lopes e Alves (2014, p. 2) afirmam que: "ao conhecer a História 
da Matemática, o aluno a percebe como uma ciência desenvolvida pela humanidade, passível de erros e construída a partir de muitas tentativas em solucionar problemas cotidianos".

Ainda os Questionados K e P salientam que a utilização da História da Matemática não deve ser resumida a datas e nomes, para que possa enriquecer a aula e não simplesmente apresentar dados a serem memorizados ou reproduzidos:

QK: Acredito que sim, apenas deve haver o cuidado de não cair na abordagem por ela mesma, como por exemplo, a exposição da aula por meio de projetor quando pode ser feita da mesma maneira utilizando "quadro-giz".

QP: Sim, na compreensão dos conteúdos não na simples repetição de exemplos meramente decorados para avaliação.

Pelo contexto, infere-se da fala do Questionado K que o uso do "projetor" represente figurativamente a exposição dos dados históricos em desconexão com o conteúdo matemático, o qual estaria sendo desenvolvido usando "quadro e giz", e poderia, simultaneamente, ser contextualizado com elementos históricos.

Outras das respostas afirmativas que se destacam são as dos respondentes $B, C$ e $F$, que consideram que a História da Matemática ajudaria os alunos a compreender a construção do conhecimento matemático, assim desmistificando-o, e contribuir para o desenvolvimento do pensamento crítico e do espírito de reflexão:

QB: Acredito que sim, pois a história da matemática pode estar desenvolvendo o espírito crítico, além de auxiliar na aprendizagem onde os alunos podem compreender os conceitos e ideias de teorias $e$ teoremas que muitas vezes são apenas apresentados em sua versão final já pronta.

QC: Sim, pois o Ensino Básico deve formar os estudantes não apenas com os métodos matemáticos, mas sim com todo o contexto da matemática, incluindo a história, e fazer o estudante refletir quanto a isso.

QF: Creio que sim. Seria mais um instrumento para desmistificar a matemática e fazer com que os alunos entendam toda construção que envolve tudo que estão estudando no assunto.

Nesse sentido, os PCN afirmam que a História da Matemática pode contribuir para o resgate da identidade cultural, trazendo importante valor ao mostrar a Matemática como uma ciência desenvolvida pela humanidade ao longo do tempo:

Além disso, conceitos abordados em conexão com sua história constituem-se veículos de informação cultural, sociológica e antropológica de grande valor formativo. A História da Matemática é, nesse sentido, um instrumento de resgate da própria identidade cultural. (BRASIL, 1998, p. 42)

Assim, a História da Matemática pode contribuir para ajudar o estudante a refletir sobre conceitos matemáticos e também ter um olhar mais crítico sobre os mesmos. Além disso, permitiria aos alunos perceber a Matemática como uma área construída (e em construção) e de impacto cultural e social.

Valente (2013) observa essa falta de registros e conhecimentos que tratam da História da Matemática no cotidiano da Educação Básica, o que reforça a ideia de que ainda é pouco explorada. Então "parece 
que ainda não há exemplos, e conhecimento acumulado sobre experiências tratadas no cotidiano escolar em termos do uso da História da Matemática" (VALENTE, 2013, p. 12). Ainda dentre os que consideram de suma importância a abordagem histórica no decorrer do ensino da Matemática, 0 Questionado N enfoca, muito apropriadamente, na interdisciplinaridade com a Filosofia:

QN: Dentro das aulas de Matemática considero muito importante, mas acho que poderia ser abordado nas aulas de filosofia também, pois grande parte dos matemáticos de renome eram também filósofos, são duas áreas de pensamento e que por muito tempo estiveram muito ligadas.

Em concordância com a citação anterior, Fiorentini e Lorenzato (2012) afirmam que a Educação Matemática tem ligações com diversas áreas, já que Educação Matemática é um campo abrangente:

[...] "educação matemática" é atribuída ao fato de que este tem conotação mais abrangente, podendo significar tanto um fenômeno ou uma atividade educacional que visa a formação integral do ser, quanto uma área multidisciplinar de conhecimento, em que a Matemática é uma disciplina entre outras, tais como a Psicologia, a Filosofia, a História, [....]. (FIORENTINI; LORENZATO, 2012, p. 12)

Por fim, o respondente $L$ aborda uma questão relevante, sobre a presença de elementos históricos no livro didático:

QL: Sim, principalmente quando tem a abordagem no livro didático. Quando não tem e se a gente não lembrar no momento da explicação do conteúdo ou na preparação acaba passando batido, então é importante que os conteúdos ao serem ministrados tenham também um foco no livro didático porque muitas vezes a gente não consegue lembrar de tudo ou a gente acaba não tendo tempo para pesquisar e adiciona isso no nosso conteúdo abordado.

A primeira frase subentende que o respondente $L$ atribuiu importância à abordagem da História da Matemática principalmente (ou somente) se ela estiver presente no livro didático. Porém, no contexto da sua justificativa (e também por respostas anteriores, como a fornecida à Pergunta 6, na qual dedica-se a exemplificar detalhadamente uma situação em que utiliza a História da Matemática como instrumento pedagógico), transparece que ele atribui importância à abordagem histórica, que entende que o próprio livro didático deveria fornecer aporte robusto ao professor, para que não fique completamente ao seu encargo e à mercê da sua disponibilidade de fonte e tempo para pesquisa.

Por fim, a partir das exposições e análises feitas nessa seção, entende-se que a componente curricular História da Matemática desempenha uma função importante na formação inicial do professor de matemática. Destaca-se que, apesar do grupo de consultados constituírem uma ínfima amostra de professores em formação no Brasil a pesquisa aqui relatada indica que a componente curricular História da Matemática de algum modo influencia o pensar e fazer do professor.

\section{REFLEXÕES FINAIS}

Na busca por compreender (se e) como se dá a relação entre a História da Matemática na formação inicial do professor e seu impacto na sua atuação profissional, foram coletadas, via formulário online, e analisadas as respostas de 11 licenciandos e 5 licenciados em Matemática, que já atuam na docência, a fim de verificar se fazem uso da História da Matemática em suas aulas e se entendem o processo de construção do conhecimento por meio dela. 
Com a análise das respostas obtivemos que parte dos questionados já utilizam elementos históricos como estratégia pedagógica em sala de aula, para motivação, mobilização do conhecimento ou contextualização e, os que não utilizam, manifestaram a intenção de vir a fazê-lo, mencionando que compreendem e reconhecem a contribuição que a História da Matemática possa Ihes oferecer. Além disso, parte dos professores questionados a utilizam em suas aulas sem perceber a importância do trabalho que desenvolvem junto aos estudantes da Educação Básica.

Em geral, como potencialidades do seu uso, os respondentes destacaram a mobilização do conhecimento, a instigação da curiosidade e, principalmente, a construção do conhecimento com e pelos alunos. Ainda, um grupo dos respondentes, que também atua no Ensino Superior, citou exemplos e mencionaram potencialidades que também podem ser exploradas na graduação, evidenciando o alcance que pode ter essa ferramenta.

De modo geral, pode-se explorar o viés de que a História da Matemática oportuniza uma significação aos estudos feitos em sala de aula e também fornece aos estudantes desenvolver uma maior consciência do mundo e da realidade, da construção dos conhecimentos e também dos artefatos que foram desenvolvidos em outras épocas e que estão disponíveis hoje.

Por fim, a presente pesquisa teve como propósito compartilhar uma discussão e provocar reflexões na comunidade da Educação Matemática sobre a formação inicial de professores no que tange à componente curricular História da Matemática. Considera-se que o convite à extensão e planejamento de ações, na formação inicial de professores de matemática, que integrem o conhecimento em vez de fragmentá-lo possa contribuir no futuro desses profissionais da educação. Tal sentimento estendese de forma natural aos estudantes da escola básica, os quais terão sua formação conduzida por profissionais mais integrados e plurais a respeito do entendimento da construção do conhecimento pela humanidade.

\section{REFERÊNCIAS}

AABOE, A. Episódios da História Antiga da Matemática. 3. ed. Rio de Janeiro: SBM Editora, 2013.

BRASIL. Secretaria de Educação Fundamental. Parâmetros Curriculares Nacionais: Matemática. Brasília: MEC/SEF, 1998.

DENZIN, N.; LINCOLN, Y. S. The Sage Handbook of Qualitative Research. Thousand Oaks, CA: 2005. FIORENTINI, D.; LORENZATO, S. Investigação em Educação Matemática: percursos teóricos e metodológicos. 3. ed. Campinas, SP: Autores Associados, 2012.

FLICK, U. Desenho da Pesquisa Qualitativa. 3. ed. São Paulo: Artmed Editora S.A., 2009.

GERHARDT, T. E.; SILVEIRA, D. T. Métodos de Pesquisa. 1. ed. Porto Alegre: Universidade Federal do Rio Grande do Sul, 2009. Disponível em <http://www.ufrgs.br/cursopgdr/downloadsSerie/derad005.pdf>. Acesso: 21 abr. 2018.

LEIVAS, J. C. P.; CURY, H. N. Transposição Didática: exemplos em educação matemática. Educação Matemática em Revista - RS, n. 10, v. 1, p.65-74, 2009. Disponível em: <http://sbemrs.org/revista/index.php/2011_1/article/download/22/21>. Acesso: 12 mar. 2018. 
LOPES, L. S.; ALVES, A. M. M. A História da Matemática em Sala de Aula: Propostas de Atividades para a Educação Básica. XX EREMAT, Bagé, P. 320-330, 2014. Dispo-nível em:<https://eventos.unipampa.edu.br/eremat/files/2014/12/MC_Lopes_01359155031.pdf>. Acesso: 10 nov. 2018.

MIGUEL, A.; MIORIM, M. A. História na Educação Matemática: propostas e desafios. Belo Horizonte: Autêntica, 2004.

NARDIN, A. C. Materiais Didáticos Probio/ea: do saber sábio ao saber a ensinar. Instituto Federal Sul-rio-grandense, Pelotas: 2012. Disponível em:<http://docplayer.com.br/8640914-Materiais-didaticosprobio-ea-do-saber-sabio-ao-saber-aensinar.html>. Acesso: 12 mar. 2018.

PAIS, L. C. Didática da Matemática: uma análise da influência francesa. 3. ed. Belo Horizonte: Autêntica, 2011.

SILVA, A. A. A História da Matemática na formação inicial do professor de matemática. 2018. $66 f$. Trabalho de Conclusão de Curso (Licenciatura em Matemática). Instituto Federal de Educação, Ciência e Tecnologia do Rio Grande do Sul. Campus Caxias do Sul. Caxias do Sul. 2018.

TOUJA, P. W. Matemática: Do que trata? Para que serve? Qual sua História? 2014. 34f. Trabalho de Conclusão de Curso (Licenciatura em Matemática). Universidade Federal do Rio Grande do Sul. Porto Alegre. 2014.

VALENTE, W. R. Oito temas sobre História da educação matemática. REMATEC, Natal, v. 8, n.12, p. 2250, jan-jun. $2013 . \quad$ Disponível em: <https://repositorio.ufsc.br/bitstream/handle/123456789/160384/VALENTE,\%20W\%20\%200ito\%20tema s\%20em\%20Hist\%C3\%B3ria\%20da\%20Educa\%C3\%A7\%C3\%A30\%20Matem\%C3\%A1tica.pdf?sequenc e=3>. Acesso: 03 mar. 2018. 